\title{
Modeling Hydrogen Evolution Reaction Kinetics Through Explicit Water-Metal Interfaces
}

Michael T. Tang*1,2, Xinyan Liu*2, Yongfei Ji ${ }^{4}$, Jens K. Norskov ${ }^{3}$, and Karen Chan $^{3}$

${ }^{1}$ Department of Material Science and Engineering, Stanford University, Stanford, California 94305

${ }^{2}$ SUNCAT Center for Interface Science and Catalysis, SLAC National Accelerator Laboratory, Menlo Park, California 94025

${ }^{3}$ CatTheory section, Department of Physics, Technical University of Denmark, Lyngby, Denmark

${ }^{4}$ School of Chemistry and Chemical Engineering, Guangzhou University, Guangzhou, China

December 11, 2020

* These authors contributed equally

\section{Supplemental Tables}

Table S1: Unscaled transition state energies used in Figure 2(b), to model HER kinetics, in $\mathrm{eV}$. The following dataset is modeled after metal surfaces under low $\mathrm{H}^{*}$ coverage $\left(1 \mathrm{H}^{*} / 9\right.$ sites on fcc(111), $1 \mathrm{H}^{*} / 3$ sites on $\left.\mathrm{fcc}(211)\right)$

\begin{tabular}{lcccccc}
\hline Metal Surface & $E_{H *}$ & $E_{C O *}$ & $E_{O H *}$ & $\begin{array}{l}\text { Volmer } \\
{[\mathrm{eV}]}\end{array}$ & $\begin{array}{l}\text { Heyrovsky } \\
{[\mathrm{eV}]}\end{array}$ & $\begin{array}{l}\text { Tafel } \\
{[\mathrm{eV}]}\end{array}$ \\
\hline $\mathrm{Ag}(111)$ & 0.42 & -0.04 & 0.04 & 1.27 & 0.80 & 1.77 \\
$\mathrm{Cu}(111)$ & 0.01 & -0.48 & -0.01 & 0.87 & 0.41 & 0.88 \\
$\operatorname{Ir}(111)$ & -0.22 & -1.54 & 0.35 & 0.28 & 0.26 & 0.14 \\
$\operatorname{Pd}(111)$ & -0.30 & -1.74 & 0.44 & 0.53 & 0.22 & 0.38
\end{tabular}




\begin{tabular}{lllllll}
$\mathrm{Pt}(111)$ & -0.19 & -1.37 & 0.78 & 0.25 & 0.26 & 0.27 \\
$\mathrm{Rh}(111)$ & -0.33 & -1.68 & 0.10 & 0.37 & 0.20 & 0.00 \\
$\mathrm{Ni}(111)$ & -0.36 & & -0.12 & & & 0.33 \\
$\mathrm{Ag}(211)$ & 0.39 & & 0.16 & 0.91 & 0.82 & 1.57 \\
$\mathrm{Au}(211)$ & 0.28 & & 0.55 & 0.75 & 0.66 & 1.07 \\
$\mathrm{Cu}(211)$ & -0.03 & -0.47 & 0.57 & 0.45 & 0.85 \\
$\mathrm{Pt}(211)$ & -0.44 & 0.04 & 0.00 & -0.02 & -0.19 \\
\hline
\end{tabular}

Table S2: Unscaled transition state energies used in Figure 2(b), to model HER kinetics, in $\mathrm{eV}$. The following dataset is modeled after metal surfaces under high $\mathrm{H}^{*}$ coverage $\left(8 \mathrm{H}^{*} / 9\right.$ sites on fcc(111))

\begin{tabular}{lclll}
\hline Metal Surface & $E_{H *}$ & $\begin{array}{l}\text { Volmer } \\
{[\mathrm{eV}]}\end{array}$ & $\begin{array}{l}\text { Heyrovsky } \\
{[\mathrm{eV}]}\end{array}$ & $\begin{array}{l}\text { Tafel } \\
{[\mathrm{eV}]}\end{array}$ \\
\hline $\mathrm{Ag}(111)$ & 0.64 & 1.34 & 1.05 & 2.10 \\
$\mathrm{Cu}(111)$ & 0.25 & 0.97 & 0.82 & 1.42 \\
$\operatorname{Ir}(111)$ & -0.04 & 0.54 & 0.47 & \\
$\operatorname{Pd}(111)$ & -0.08 & 0.66 & 0.62 & \\
$\operatorname{Pt}(111)$ & -0.09 & 0.65 & 0.61 & 0.52 \\
$\operatorname{Rh}(111)$ & -0.27 & 0.50 & 0.26 & \\
\hline
\end{tabular}

Table S3: Scaled transition state energies of all reaction intermediates used in kinetics, in eV. The following dataset is modeled after metal slabs under low $\mathrm{H}^{*}$ coverage. Scaling relations can be found in Supplemental Note 4.

\begin{tabular}{llllll}
\hline Metal Surface & $E_{H * \text { unscaled }}$ & $E_{C O *, \text { scaled }}$ & $\begin{array}{l}\text { Volmer }_{\text {scaled }} \\
{[\mathrm{eV}]}\end{array}$ & $\begin{array}{l}\text { Heyrovsky } \\
{[\mathrm{eV}]}\end{array}$ & $\begin{array}{l}\text { Tafel } \\
{[\mathrm{eV}]}\end{array}$ \\
\hline $\mathrm{Au}(111)$ & 0.39 & 0.2 & 1.06 & 0.82 & 1.58 \\
$\mathrm{Ag}(111)$ & 0.42 & 0.13 & 1.09 & 0.85 & 1.64 \\
$\mathrm{Cu}(111)$ & 0.01 & -0.8 & 0.67 & 0.50 & 0.80 \\
$\mathrm{Ir}(111)$ & -0.25 & -1.48 & 0.40 & 0.28 & 0.27 \\
$\operatorname{Pd}(111)$ & -0.30 & 1.60 & 0.35 & 0.23 & 0.16 \\
$\operatorname{Pt}(111)$ & -0.19 & -1.33 & 0.46 & 0.33 & 0.39 \\
$\operatorname{Rh}(111)$ & -0.33 & -1.67 & 0.32 & 0.21 & 0.10 \\
$\mathrm{Cu}: \operatorname{Pt}(111)$ & -0.09 & -1.09 & 0.56 & 0.41 & 0.58 \\
$\operatorname{Ni}(111)$ & -0.36 & -1.75 & 0.29 & 0.18 & 0.04 \\
$\operatorname{Ag}(211)$ & 0.39 & & 1.06 & 0.83 & 1.58 \\
$\operatorname{Au}(211)$ & 0.28 & & 0.95 & 0.73 & 1.36
\end{tabular}




\begin{tabular}{lllll}
$\mathrm{Cu}(211)$ & -0.03 & 0.63 & 0.46 & 0.72 \\
$\mathrm{Pt}(211)$ & -0.44 & 0.20 & 0.11 & -0.13 \\
\hline
\end{tabular}

Table S4: A summary of the free energy barriers ( $0 \mathrm{~V}$ vs RHE) on various metal surfaces from the scaled microkinetic model at low $\mathrm{H}^{*}$ coverage. Volmer and Heyrovsky barriers are referenced to bulk protons and electrons in aqueous solution ${ }^{1}$.

\begin{tabular}{llll}
\hline Metal Surface & $\begin{array}{l}\text { Volmer } \\
{[\mathrm{eV}]}\end{array}$ & $\begin{array}{l}\text { Heyrovsky } \\
{[\mathrm{eV}]}\end{array}$ & $\begin{array}{l}\text { Tafel } \\
{[\mathrm{eV}]}\end{array}$ \\
\hline $\mathrm{Ag}(111)$ & 1.25 & 0.62 & 0.83 \\
$\mathrm{Au}(111)$ & 1.22 & 0.62 & 0.81 \\
$\mathrm{Cu}(111)$ & 0.82 & 0.67 & 0.79 \\
$\mathrm{Ir}(111)$ & 0.55 & 0.72 & 0.80 \\
$\mathrm{Pd}(111)$ & 0.50 & 0.72 & 0.79 \\
$\mathrm{Pt}(111)$ & 0.61 & 0.71 & 0.80 \\
$\operatorname{Rh}(111)$ & 0.47 & 0.73 & 0.79 \\
$\mathrm{Cu}: \operatorname{Pt}(111)$ & 0.75 & 0.72 & 0.80 \\
$\mathrm{Ni}(111)$ & 0.45 & 0.74 & 0.79 \\
$\mathrm{Ag}(211)$ & 1.26 & 0.68 & 0.81 \\
$\mathrm{Au}(211)$ & 1.14 & 0.69 & 0.80 \\
$\mathrm{Cu}(211)$ & 0.81 & 0.71 & 0.80 \\
$\mathrm{Pt}(211)$ & 0.36 & 0.74 & 0.77 \\
\hline
\end{tabular}

Table S5: Vibration frequencies of all reaction intermediates used in kinetics

\begin{tabular}{lr}
\hline Species & Frequencies $(\mathrm{cm}-1)$ \\
\hline $\mathrm{H}^{*}$ & $459.5,563.0,995.3$ \\
$\mathrm{CO}^{*}$ & $68.7,99.7,261.1,268.2,306.9,2040.0$ \\
OH$^{*}$ & $35.4,126.8,307.9,511.8,534.0,3660.9$ \\
Volmer TS & $915.4,1093.9$ \\
Heyrovsky TS & $197.8,747.1,1151.9,1311.0,1491.8$ \\
Tafel TS & $129.1,218.3,426.7,4083.2$ \\
\hline
\end{tabular}

Table S6: Coverage-dependent CO* adsorption energies on a $3 \times 3$ supercell of $\mathrm{Pt}(111)$ with only the topmost layer relaxed. $\mathrm{CO}^{*}$ are adsorbed on $\mathrm{Pt}(111)$ in hollow sites up to $\theta_{C O *}=$ $0.28 \mathrm{ML}$. CO* is then adsorbed in mixed configurations up to $\theta_{C O *}=0.83 \mathrm{ML}$. 


\begin{tabular}{rr} 
CO* coverage $(\mathrm{ML})$ & $\mathrm{E}_{\text {diff }}(\mathrm{eV})$ \\
\hline 0.06 & -1.60 \\
0.17 & -1.50 \\
0.28 & -1.44 \\
0.39 & -1.43 \\
0.50 & -1.01 \\
0.61 & -0.50 \\
0.72 & -0.29 \\
0.83 & 0.65 \\
\hline
\end{tabular}

Table S7: Work functions and charges used for charge-extrapolating Volmer barriers across the (111) and (211) metal surfaces considered in this study.

\begin{tabular}{lrrrrrr}
\hline Volmer & IS WF & TS WF & FS WF & q(IS) & q(TS) & q(FS) \\
\hline $\mathrm{Ag}(111) 0.11 \mathrm{ML}$ & 2.561 & 3.597 & 4.366 & 0.598 & 0.020 & -0.090 \\
$\mathrm{Cu}(111) 0.11 \mathrm{ML}$ & 2.555 & 4.429 & 5.531 & 0.607 & 0.053 & -0.070 \\
$\mathrm{Ir}(111) 0.11 \mathrm{ML}$ & 2.857 & 4.897 & 5.552 & 0.672 & 0.071 & -0.054 \\
$\mathrm{Rh}(111) 0.11 \mathrm{ML}$ & 3.433 & 4.474 & 5.793 & 0.608 & 0.052 & -0.058 \\
$\mathrm{Pd}(111) 0.11 \mathrm{ML}$ & 3.568 & 4.108 & 5.636 & 0.616 & 0.050 & -0.046 \\
$\mathrm{Pt}(111) 0.11 \mathrm{ML}$ & 4.005 & 5.666 & 5.817 & 0.676 & 0.101 & -0.013 \\
$\mathrm{Ag}(111) 0.88 \mathrm{ML}$ & 2.822 & 3.664 & 4.293 & 0.706 & 0.085 & -0.050 \\
$\mathrm{Cu}(111) 0.88 \mathrm{ML}$ & 2.877 & 4.085 & 5.105 & 0.715 & 0.119 & -0.040 \\
$\mathrm{Ir}(111) 0.88 \mathrm{ML}$ & 3.055 & 3.916 & 5.441 & 0.689 & 0.114 & -0.017 \\
$\mathrm{Rh}(111) 0.88 \mathrm{ML}$ & 3.561 & 4.209 & 5.073 & 0.682 & 0.107 & -0.033 \\
$\mathrm{Pd}(111) 0.88 \mathrm{ML}$ & 3.294 & 4.657 & 5.784 & 0.711 & 0.094 & -0.028 \\
$\mathrm{Pt}(111) 0.88 \mathrm{ML}$ & 2.907 & 4.281 & 5.365 & 0.728 & 0.109 & -0.024 \\
$\mathrm{Ag}(211) 0.33 \mathrm{ML}$ & 2.378 & 3.266 & 4.230 & 0.594 & 0.200 & -0.340 \\
$\mathrm{Au}(211) 0.33 \mathrm{ML}$ & 2.812 & 4.180 & 6.333 & 0.685 & 0.168 & -0.071 \\
$\mathrm{Cu}(211) 0.33 \mathrm{ML}$ & 2.041 & 3.225 & 4.180 & 0.567 & 0.144 & -0.388 \\
$\mathrm{Pt}(211) 0.33 \mathrm{ML}$ & 3.488 & 5.351 & 5.701 & 0.675 & 0.079 & -0.100 \\
\hline
\end{tabular}

Table S8: Work functions and charges used for charge-extrapolating Volmer barriers across the (111) and (211) metal surfaces considered in this study.

\begin{tabular}{|c|c|c|c|c|c|c|}
\hline Heyrovsky & IS WF & TS WF & FS WF & $q($ IS $)$ & $\mathrm{q}(\mathrm{TS})$ & $\mathrm{q}(\mathrm{FS})$ \\
\hline $\mathrm{Ag}(111) 0.11 \mathrm{ML}$ & 2.399 & 3.222 & 4.462 & 0.614 & 0.454 & -0.095 \\
\hline $\mathrm{Cu}(111)$ 0.11 ML & 2.476 & 3.972 & 5.579 & 0.627 & 0.455 & 0.045 \\
\hline
\end{tabular}




\begin{tabular}{lllllll}
$\operatorname{Ir}(111) 0.11 \mathrm{ML}$ & 2.857 & 5.078 & 5.398 & 0.672 & 0.266 & -0.040 \\
$\operatorname{Rh}(111) 0.11 \mathrm{ML}$ & 3.031 & 4.245 & 4.565 & 0.621 & 0.433 & -0.050 \\
$\operatorname{Pd}(111) 0.11 \mathrm{ML}$ & 3.284 & 4.439 & 5.195 & 0.639 & 0.385 & -0.041 \\
$\operatorname{Pt}(111) 0.11 \mathrm{ML}$ & 3.278 & 5.054 & 5.671 & 0.683 & 0.292 & -0.018 \\
$\mathrm{Ag}(111) 0.88 \mathrm{ML}$ & 2.895 & 3.345 & 4.131 & 0.715 & 0.571 & -0.045 \\
$\mathrm{Cu}(111) 0.88 \mathrm{ML}$ & 3.208 & 3.775 & 5.196 & 0.710 & 0.527 & -0.011 \\
$\mathrm{Ir}(111) 0.88 \mathrm{ML}$ & 3.209 & 4.492 & 5.677 & 0.758 & 0.435 & -0.007 \\
$\operatorname{Rh}(111) 0.88 \mathrm{ML}$ & 2.593 & 4.562 & 5.875 & 0.731 & 0.396 & 0.105 \\
$\operatorname{Pd}(111) 0.88 \mathrm{ML}$ & 3.248 & 4.453 & 5.689 & 0.719 & 0.416 & 0.058 \\
$\operatorname{Pt}(111) 0.88 \mathrm{ML}$ & 2.724 & 4.136 & 5.561 & 0.726 & 0.444 & -0.030 \\
$\operatorname{Ag}(211) 0.33 \mathrm{ML}$ & 2.398 & 4.070 & 3.193 & 0.623 & -0.038 & -0.070 \\
$\mathrm{Au}(211) 0.33 \mathrm{ML}$ & 2.766 & 3.974 & 4.506 & 0.688 & 0.208 & -0.034 \\
$\mathrm{Cu}(211) 0.33 \mathrm{ML}$ & 2.039 & 2.990 & 4.066 & 0.567 & 0.047 & -0.068 \\
$\operatorname{Pt}(211) 0.33 \mathrm{ML}$ & 4.617 & 5.709 & 6.881 & 0.482 & 0.027 & -0.023 \\
\hline
\end{tabular}

Table S9: Charge-extrapolated energetics used determining Volmer and Heyrovsky barriers across the (111) and (211) metal surfaces considered in this study. To determine $\mathrm{E}_{T} S$, barriers are referenced to the final state, which is itself referenced to the clean slab using the computation hydrogen electrode (i.e. using gaseous $\mathrm{H}_{2}$ ). Refer to the diagram in Figure S13 for further clarification.

\begin{tabular}{lllllll}
\hline & $\begin{array}{l}\text { Volmer } \\
\mathrm{dE}\end{array}$ & $\begin{array}{l}\text { Volmer } \\
\mathrm{Ea}\end{array}$ & $\begin{array}{l}\text { Volmer } \\
\mathrm{Eb}\end{array}$ & $\begin{array}{l}\text { Heyrovsky } \\
\mathrm{dE}\end{array}$ & $\begin{array}{l}\text { Heyrovsky } \\
\mathrm{Ea}\end{array}$ & $\begin{array}{l}\text { Heyrovsky } \\
\mathrm{Eb}\end{array}$ \\
\hline $\mathrm{Ag}(111) 0.11 \mathrm{ML}$ & 0.629 & 1.511 & 0.717 & 0.222 & 0.470 & 0.375 \\
$\mathrm{Cu}(111) 0.11 \mathrm{ML}$ & 0.281 & 1.195 & 0.724 & 0.595 & 0.860 & 0.434 \\
$\mathrm{Ir}(111) 0.11 \mathrm{ML}$ & 0.292 & 0.760 & 0.398 & 0.927 & 0.984 & 0.330 \\
$\mathrm{Rh}(111) 0.11 \mathrm{ML}$ & -0.358 & 0.517 & 0.565 & 0.750 & 0.876 & 0.389 \\
$\mathrm{Pd}(111) 0.11 \mathrm{ML}$ & -0.339 & 0.766 & 0.699 & 1.038 & 1.278 & 0.390 \\
$\mathrm{Pt}(111) 0.11 \mathrm{ML}$ & -0.022 & 0.241 & 0.314 & 1.079 & 1.377 & 0.453 \\
$\mathrm{Ag}(111) 0.88 \mathrm{ML}$ & 1.067 & 1.780 & 0.575 & 0.116 & 0.392 & 0.358 \\
$\mathrm{Cu}(111) 0.88 \mathrm{ML}$ & 0.482 & 1.273 & 0.584 & -0.070 & 0.356 & 0.448 \\
$\mathrm{Ir}(111) 0.88 \mathrm{ML}$ & -0.155 & 0.670 & 0.443 & -0.101 & 0.295 & 0.489 \\
$\mathrm{Rh}(111) 0.88 \mathrm{ML}$ & -0.130 & 0.504 & 0.431 & 0.702 & 1.101 & 0.466 \\
$\mathrm{Pd}(111) 0.88 \mathrm{ML}$ & -0.065 & 0.811 & 0.611 & 0.202 & 0.763 & 0.589 \\
$\mathrm{Pt}(111) 0.88 \mathrm{ML}$ & 0.238 & 0.761 & 0.279 & 0.758 & 1.232 & 0.608 \\
$\mathrm{Ag}(211) 0.33 \mathrm{ML}$ & 0.648 & 0.956 & 0.359 & 0.023 & 0.324 & 0.618 \\
$\mathrm{Au}(211) 0.33 \mathrm{ML}$ & 0.848 & 1.148 & 0.243 & 0.695 & 0.906 & 0.231 \\
$\mathrm{Cu}(211) 0.33 \mathrm{ML}$ & 1.019 & 1.457 & 0.551 & 0.689 & 1.222 & 0.307
\end{tabular}




\begin{tabular}{|c|c|c|c|c|c|c|}
\hline $\operatorname{Pt}(211) 0.33 \mathrm{ML}$ & 0.086 & 0.361 & 0.338 & 0.554 & 0.863 & 0.070 \\
\hline
\end{tabular}




\section{Supplemental Figures}
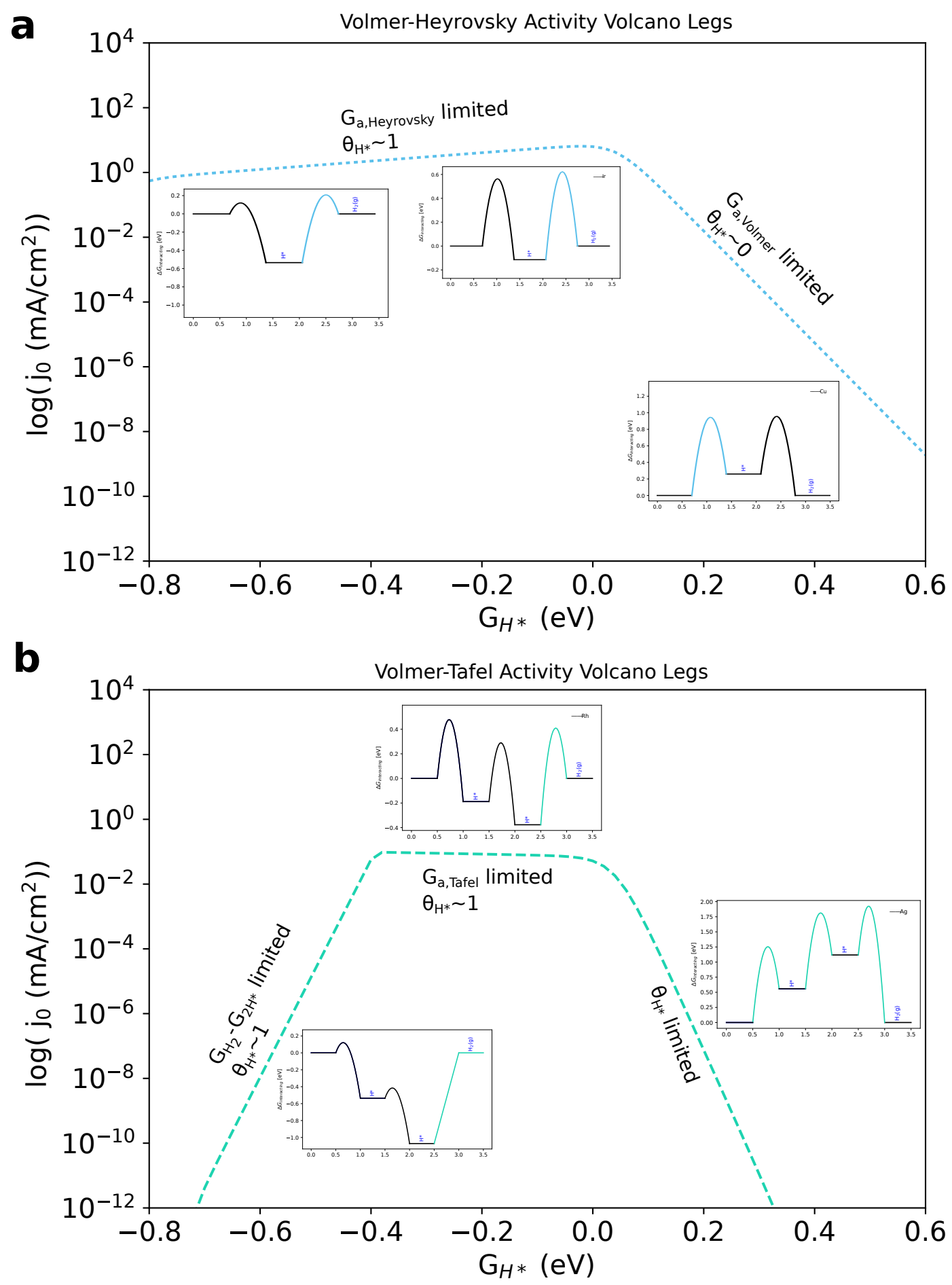

Figure S1: Illustration of how the scaled free-energy barriers and reaction energies influence the HER volcano legs. The "rate-determining step" are colored in the insets shown. 

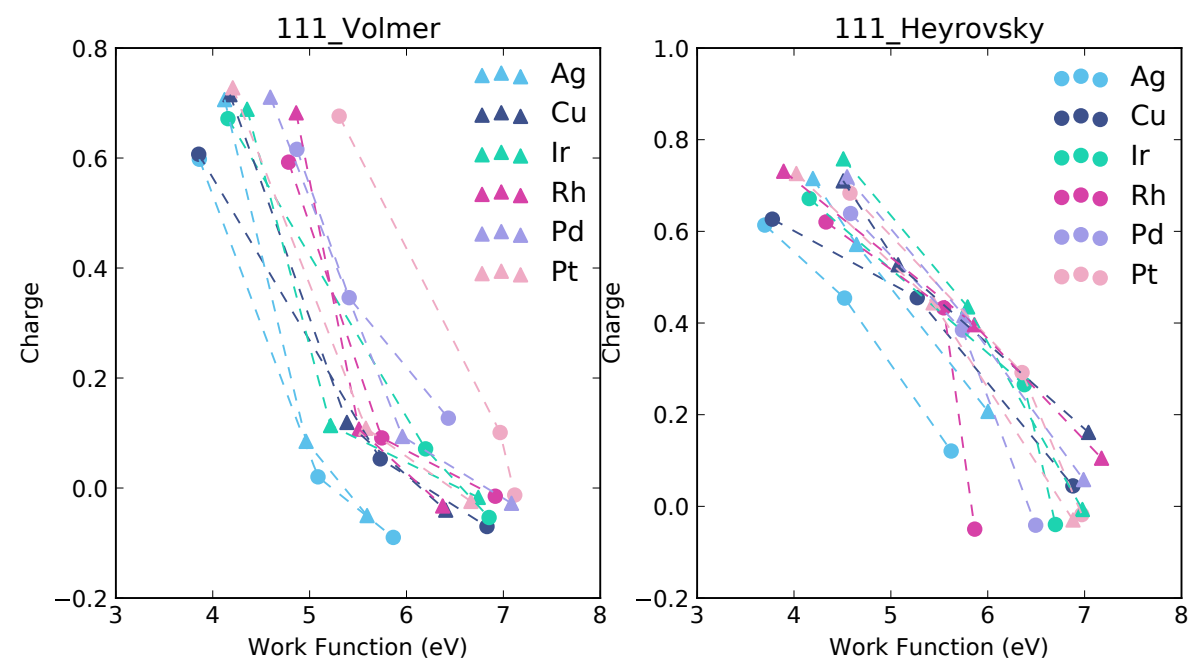

Figure S2: Initial, transition, final state charge vs. work function of Volmer and Heyrovsky reaction on (111) metal surfaces.
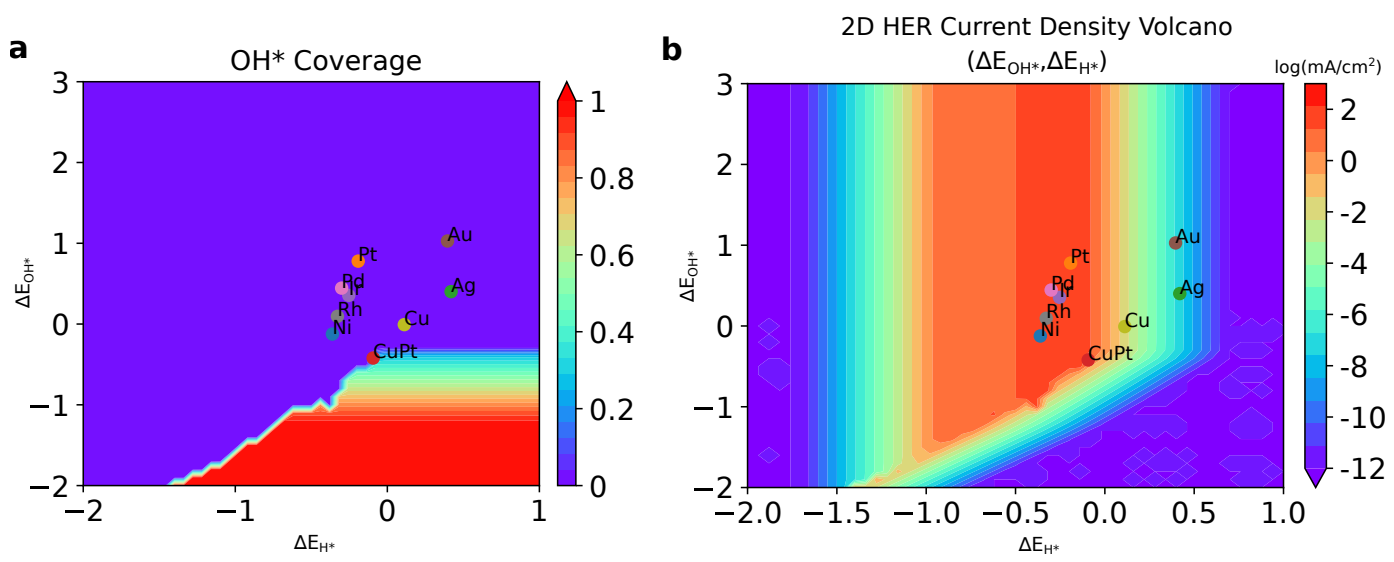

Figure S3: (a) Surface $\mathrm{OH}^{*}$ coverage map as a function of $\left(\mathrm{E}_{H *}, \mathrm{E}_{O H *}\right)$ (b) $2 \mathrm{D}\left(\mathrm{E}_{H *}, \mathrm{E}_{O H *}\right)$ current density volcano with $\mathrm{OH}^{*}$ adsorbate-adsorbate interaction. The surface coverage map and current density volcano are simulated with the scaled microkinetic model at -0.1 $\mathrm{V}$ vs $\mathrm{RHE}$, with a $\mathrm{H}_{2} \mathrm{O}$ vapor pressure of 3.5 mbar. 
Coverages at $-0.5 \mathrm{~V}$ vs. RHE $(\mathrm{pH}=0)$
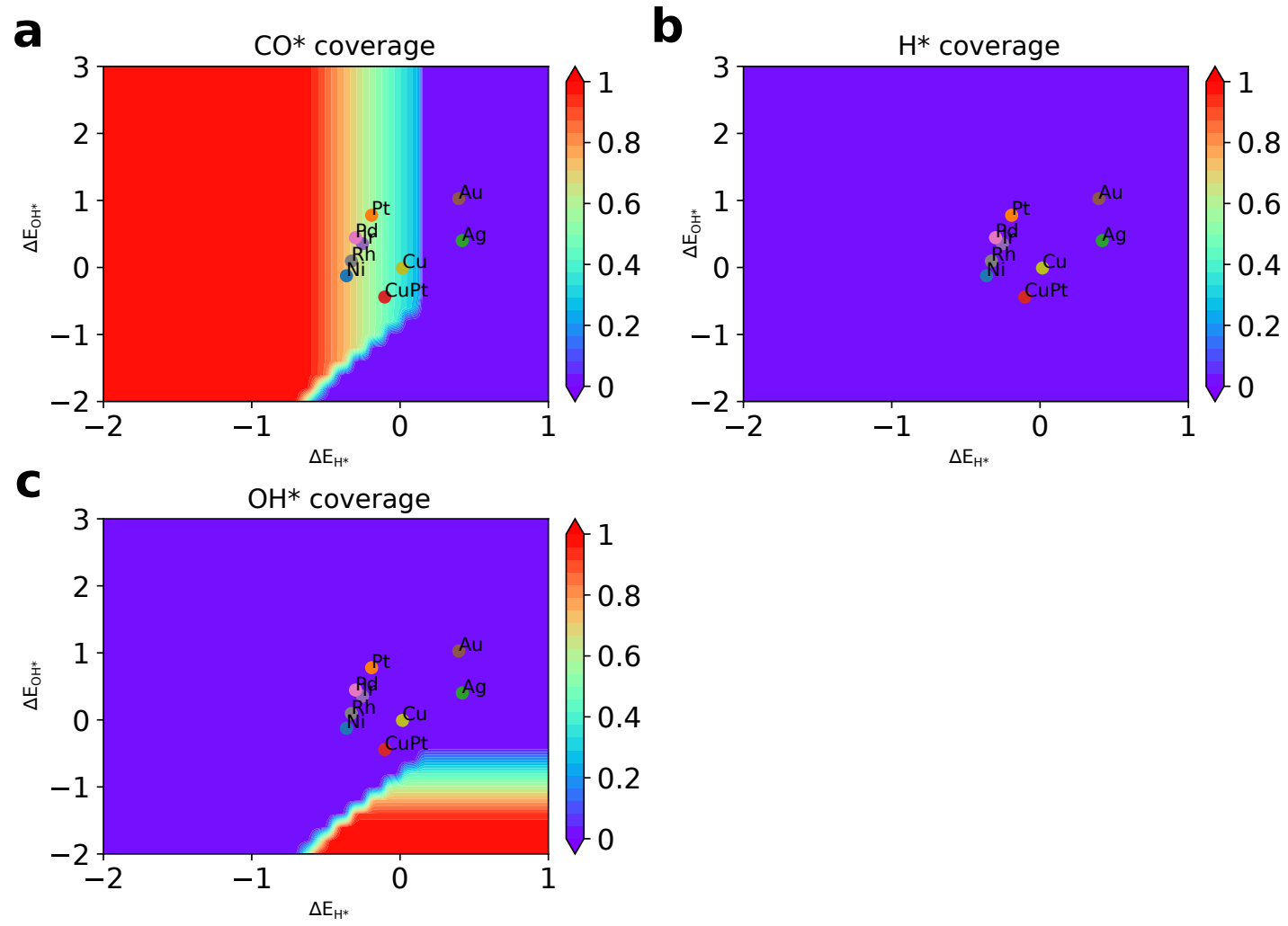

Figure S4: Surface coverage map of $\mathrm{CO}^{*}(\mathrm{a}), \mathrm{H}^{*}(\mathrm{~b})$, and $\mathrm{OH}^{*}$ (c) as a function of $\left(\mathrm{E}_{H *}, \mathrm{E}_{O H_{*}}\right)$. The surface coverage map and current density volcano are simulated for HER at $-0.5 \mathrm{~V}$ vs $\mathrm{RHE}(\mathrm{pH}=0)$ with a $\mathrm{CO}$ partial pressure of 1 mbar, and a $\mathrm{H}_{2} \mathrm{O}$ partial pressure of 3.5 mbar. 

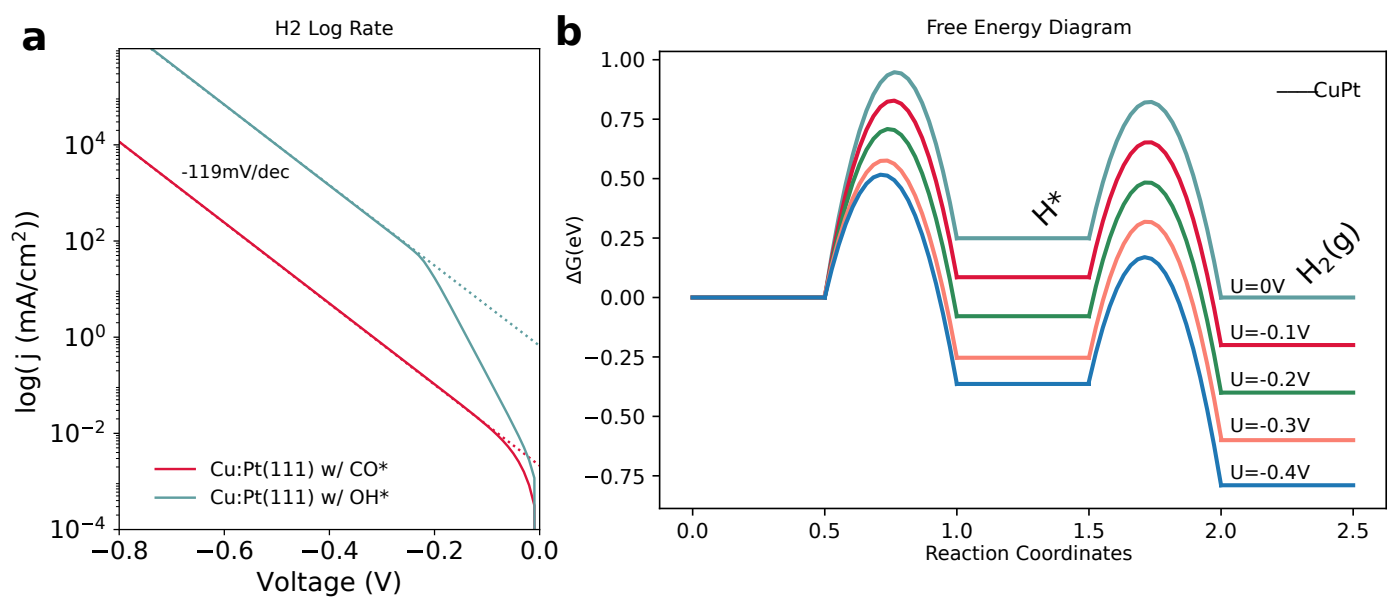

Figure S5: (a) Simulated Tafel plot on $\mathrm{Cu}: \mathrm{Pt}(111)$ with $\mathrm{OH}^{*}$ presence. The black line is with $\mathrm{CO}$ presence. As indicated with Figure $\mathrm{S} 8, \mathrm{Cu}: \mathrm{Pt}(111)$ has $\mathrm{OH}^{*}$ coverage under HER relevant conditions until potentials below $-200 \mathrm{mV}$. It takes a potential step to reduce surface $\mathrm{OH}^{*}$ to water $\left(\mathrm{OH}^{*}+\mathrm{H}^{+}+e^{-} \leftrightarrow \mathrm{H}_{2} \mathrm{O}(\mathrm{g})\right)$, which results in a simulated Tafel of around $-47 \mathrm{mV} / \mathrm{dec}$. After $-200 \mathrm{mV}$ is applied, Cu:Pt(111) Tafel slope reaches -119 $\mathrm{mV} / \mathrm{dec}$, indicative of a Volmer limited step. With CO presence, $\mathrm{Cu}: \mathrm{Pt}(111)$ saturates with $\mathrm{CO}^{*}$ rather than $\mathrm{OH}^{*}$ and reaches the Volmer limited region earlier. (b) Volmer-Heyrovsky free energy diagram from $0 \mathrm{~V}$ to $-0.4 \mathrm{~V}$ vs RHE.
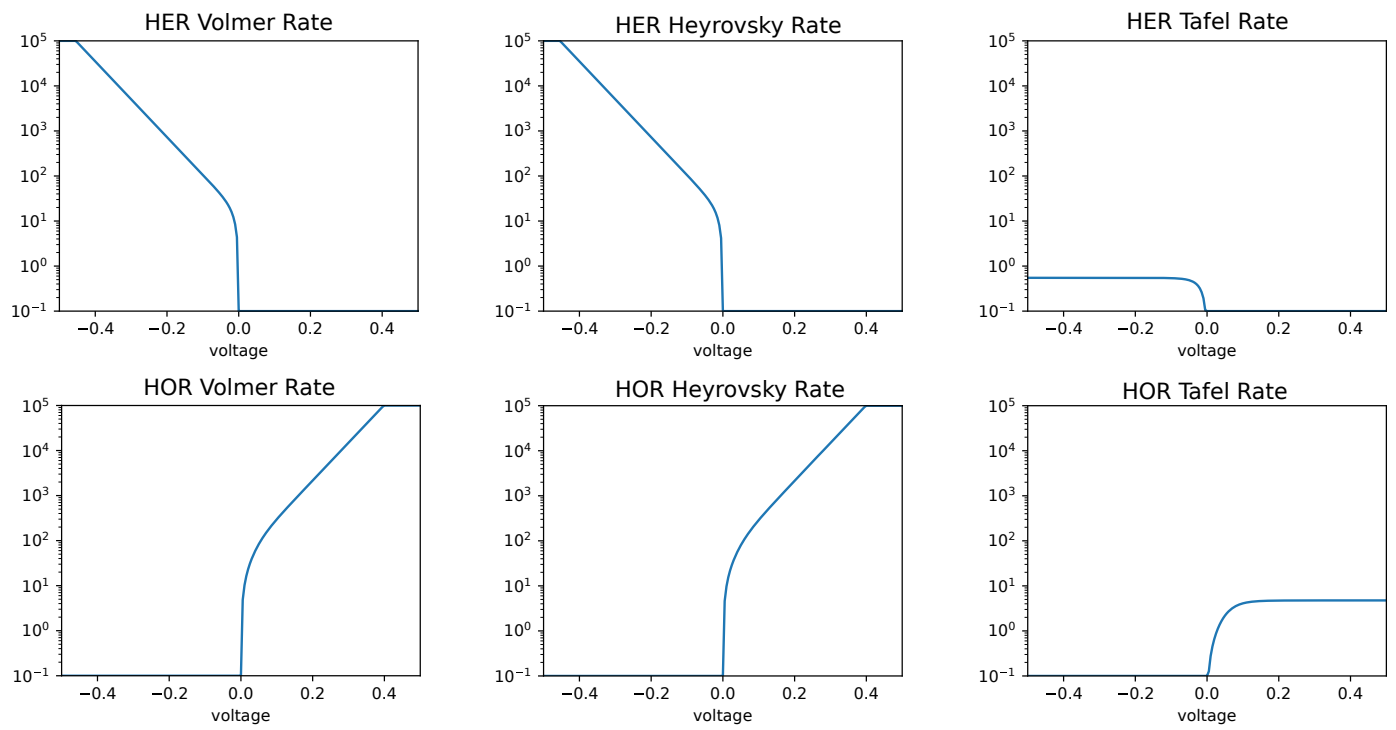

Figure S6: Simulated partial currents on $\mathrm{Pt}(111)$ through microkinetic modeling, plotted in the $\log$ scale. $\mathrm{H}_{2}$ pressure is at 1 bar. The barriers used for the model are given in Table S4: $0.61 \mathrm{eV}$ Volmer, $0.71 \mathrm{eV}$ Heyrovsky, and $0.80 \mathrm{eV}$ Tafel. The transfer coefficients of all HER elementary steps are assumed to be 0.5 . 

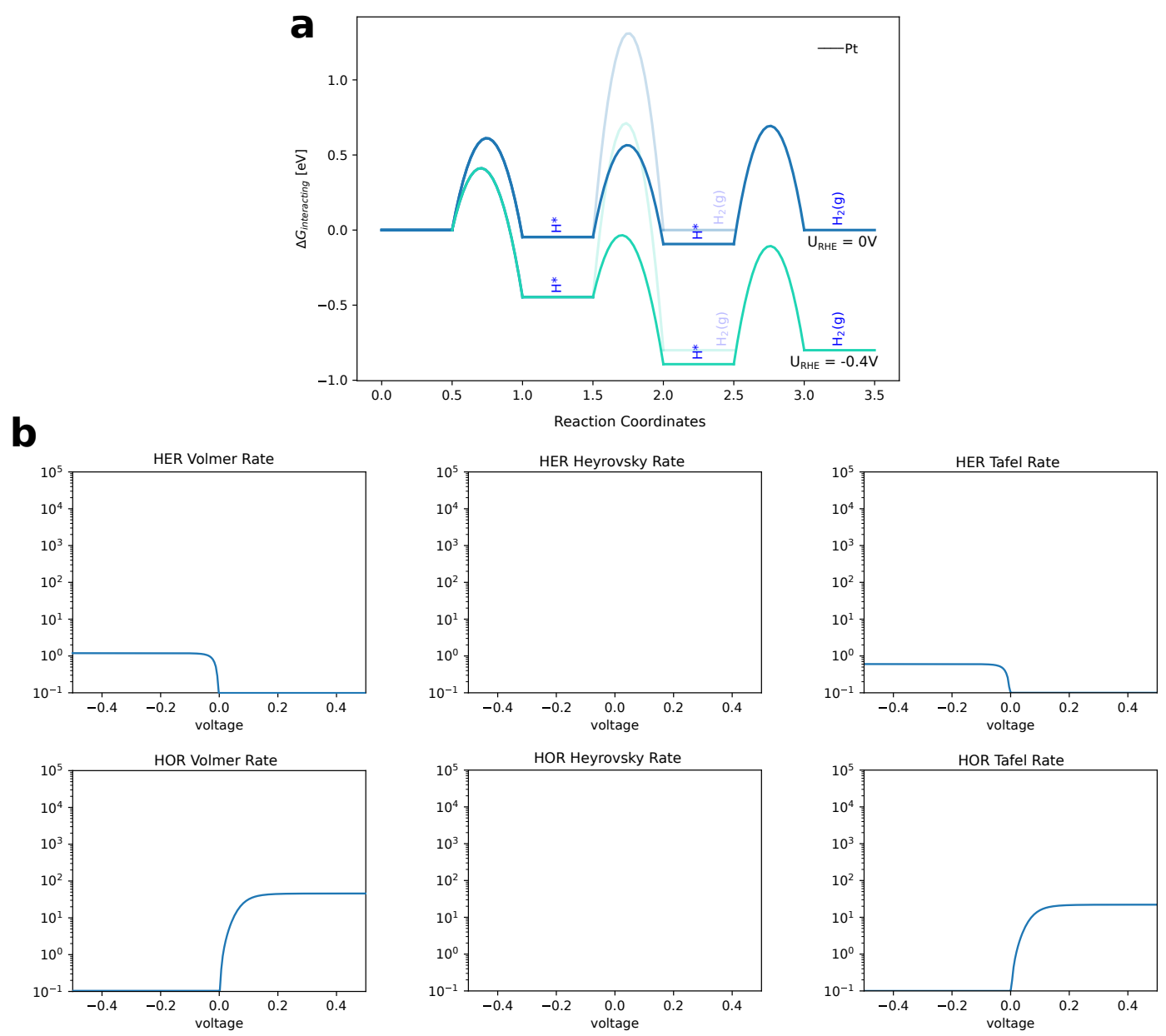

Figure S7: (a) Free energy diagram with hypothetical $1.35 \mathrm{eV}$ Heyrovsky barrier in faded blue. Volmer-Tafel route in solid blue and teal at potentials $0 \mathrm{~V}$ to $-0.4 \mathrm{~V}$ vs RHE. (b) Simulated partial currents on $\operatorname{Pt}(111)$ through microkinetic modeling, plotted in the $\log$ scale. $\mathrm{H}_{2}$ pressure is at 1 bar. The Heyrovsky barrier is arbitrarily set to a value close to values reported by ref. ${ }^{2,3}$ : $0.61 \mathrm{eV}$ Volmer, $1.35 \mathrm{eV}$ Heyrovsky, and $0.80 \mathrm{eV}$ Tafel. The transfer coefficients of all HER elementary steps are assumed to be 0.5 . 

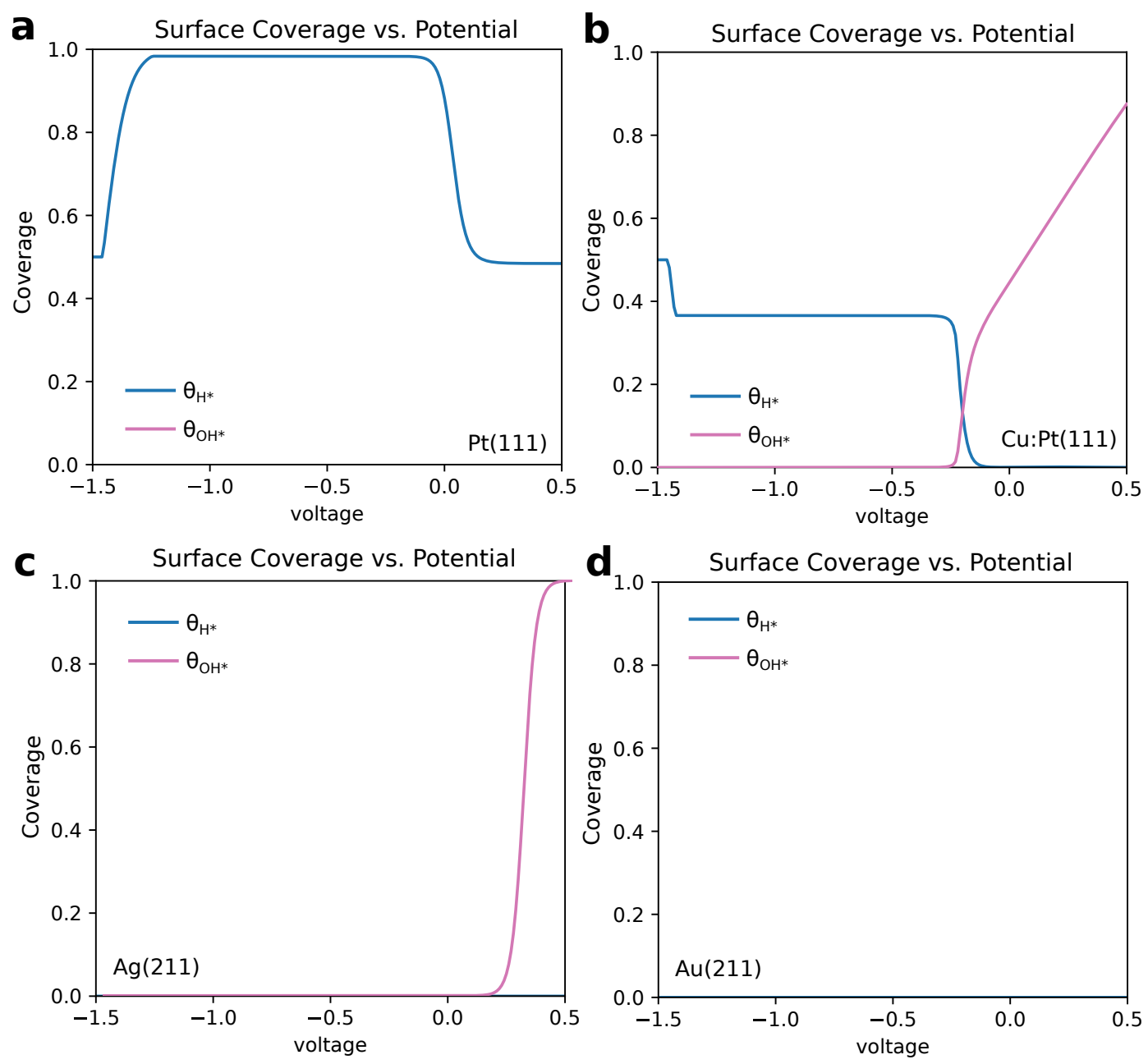

Figure S8: Simulated surface coverage as a function of applied potential on (a) $\operatorname{Pt}(111)$, (b) $\mathrm{Cu}: \mathrm{Pt}(111)$, (c) $\mathrm{Ag}(211)$, (d) and $\mathrm{Au}(211)$. There is an artifact for coverages closer to $-1.5 \mathrm{~V}$ for both $\mathrm{Pt}(111)$ and $\mathrm{Cu}: \mathrm{Pt}(111)$; at those potentials, the Volmer and Heyrovsky barriers become 0 , and because the model is under steady state conditions, the coverage of $\mathrm{H}^{*}$ becomes $0.5 \mathrm{ML} . \mathrm{H}^{*}$ coverage is plotted in blue, whereas $\mathrm{OH}^{*}$ coverage is plotted in pink. $\mathrm{Pt}(111)$ reaches close to unity with potentials as little as $50 \mathrm{mV}$. $\mathrm{Cu}: \mathrm{Pt}(111)$ requires an applied potential of around $-0.2 \mathrm{~V}$ vs RHE to reduce surface $\mathrm{OH}^{*}$ and free up sites for $\mathrm{H}^{*}$ adsorption to occur. $\mathrm{Ag}(211)$ and $\mathrm{Au}(211)$ are found to have very small $\mathrm{H}^{*}$ coverage across all potentials considered. 

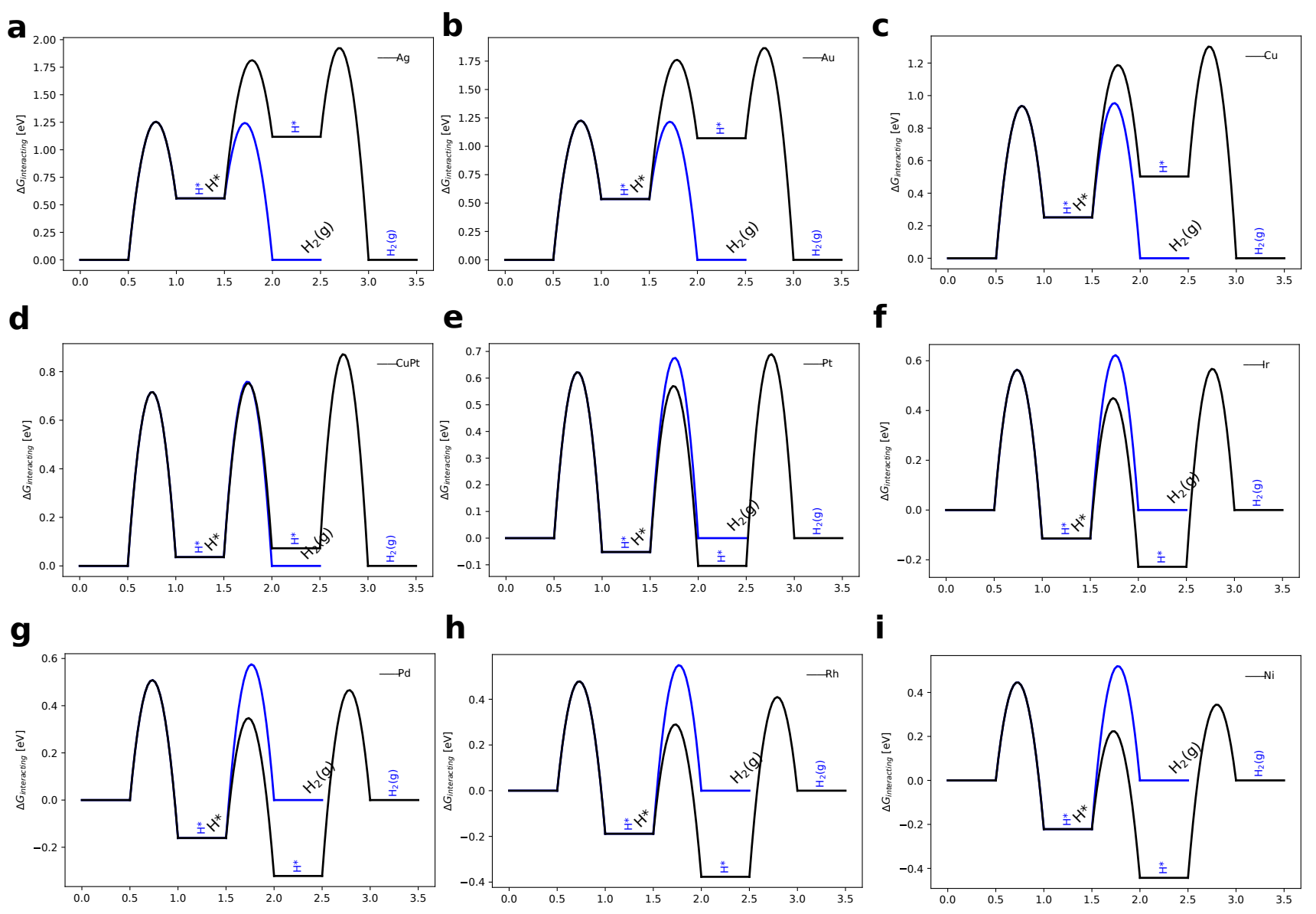

Figure S9: Scaled free energy diagrams at $0 \mathrm{~V}$ vs RHE on all (111) fcc metal surfaces considered. Blue free energy diagrams are Volmer-Heyrovsky routes and black free energy diagrams are the Volmer-Tafel routes. (a) $\mathrm{Ag}$ (b) $\mathrm{Au}$ (c) $\mathrm{Cu}$ (d) $\mathrm{Cu}: \mathrm{Pt}$ (e) Pt (f) Ir (g) Rh (h) Pd (i) Ni. See Table S4 for barrier values. 


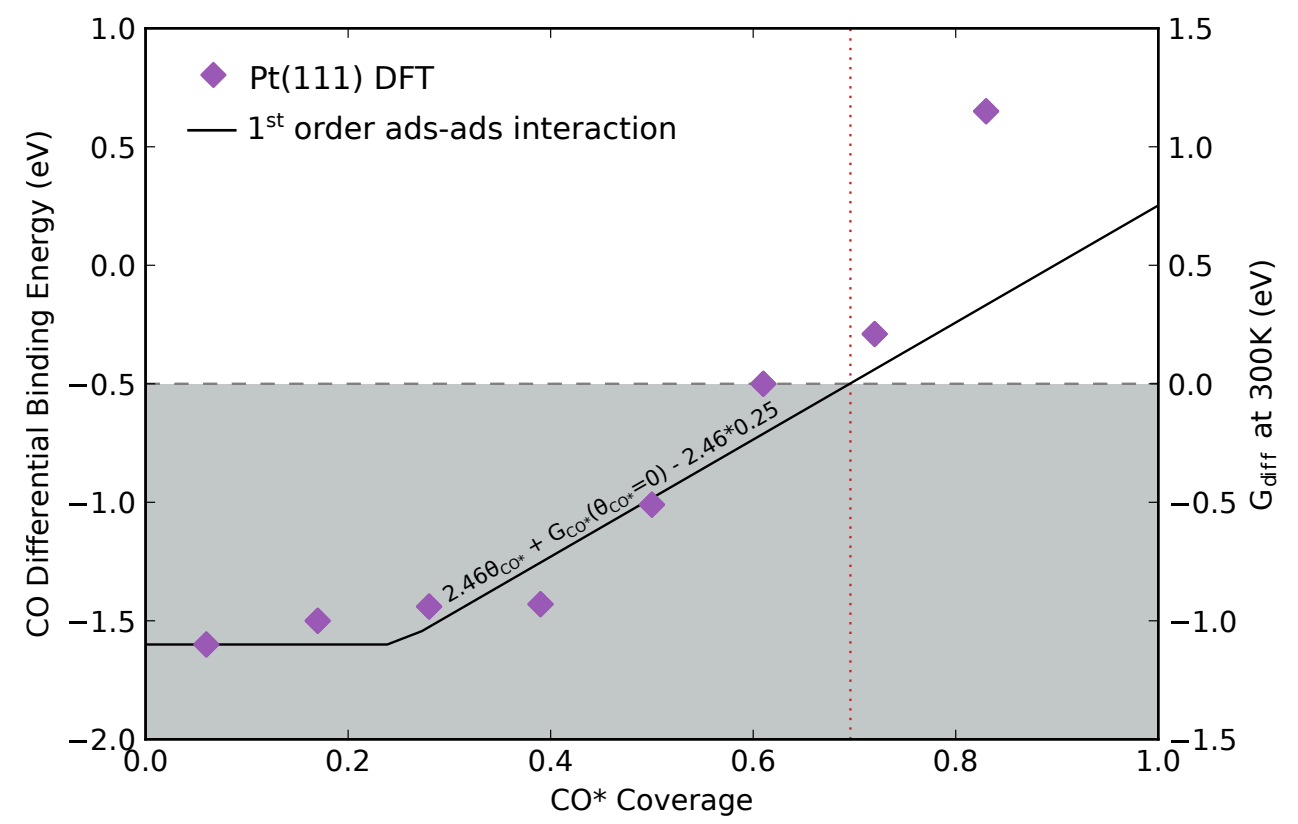

Figure S10: Coverage-dependent differential adsorption energies for $\mathrm{CO}$ adsorption on the Pt(111) surface. The purple diamonds are energetics from DFT calculations. The solid line denotes the first order adsorbate-adsorbate interaction model, expressed as a flat $\mathrm{CO}^{*}$ adsorption energy before a coverage threshold of 0.25 . After the threshold, the model shifts CO* adsorption energy according to the expression shown. The red dashed line indicates the corresponding equilibrium coverage at $\mathrm{p}_{C O(g)}$ at standard partial pressures. 


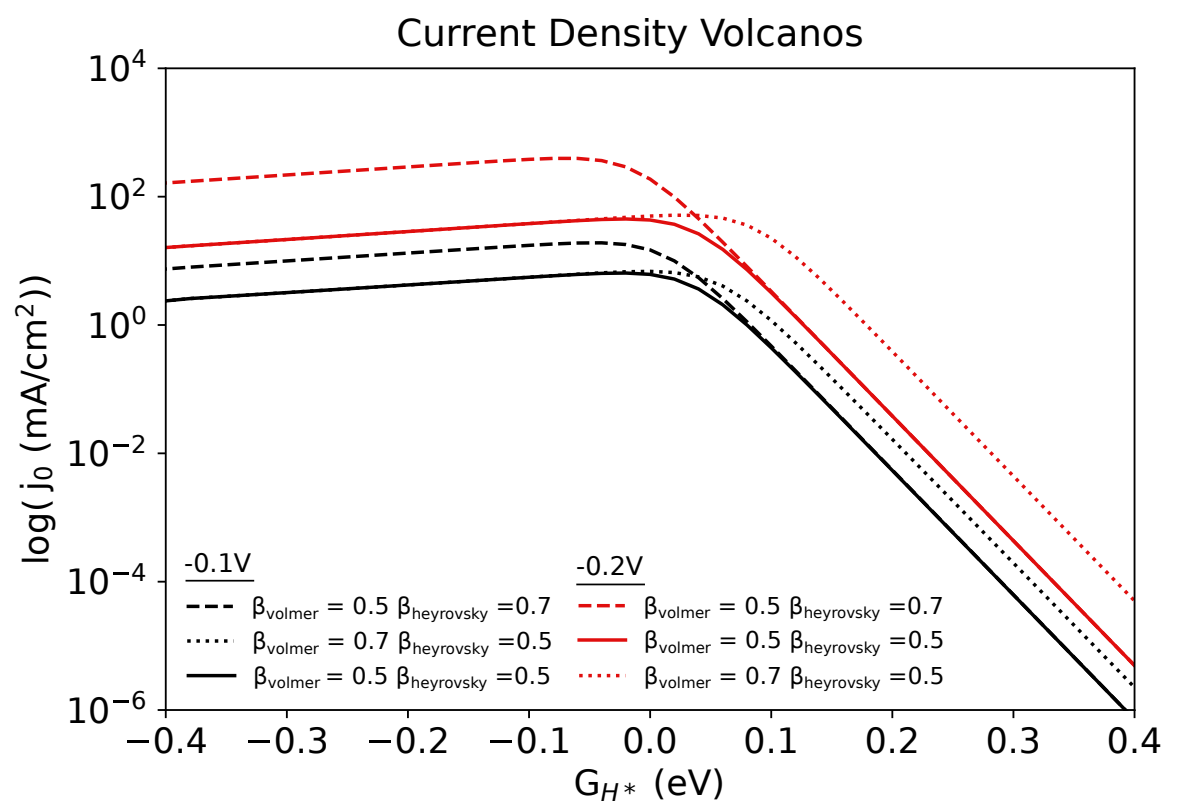

Figure S11: Sensitivity of charge transfer coefficient $\beta$ on the Volmer-Heyrovsky current density volcano peak. Volcanos are simulated at $-0.1 \mathrm{~V}$ and $-0.2 \mathrm{~V}$ vs $\mathrm{RHE}(\mathrm{pH}=0)$. Based on transition state Bader charges in Figure S2, the $\beta$ of the Volmer and Heyrovsky step may range between $0.5-0.7$. It is shown that within this beta range, there is a slight deviation in the optimal volcano peak: around $0.04 \mathrm{eV}$ for every $-0.1 \mathrm{~V}$ vs RHE. 


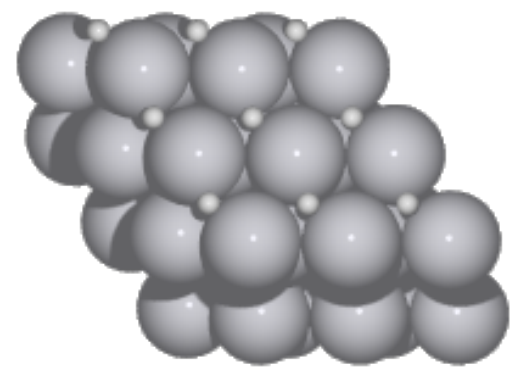

Pt(111)

$1 \mathrm{ML} \mathrm{H}^{*}$ all hollow

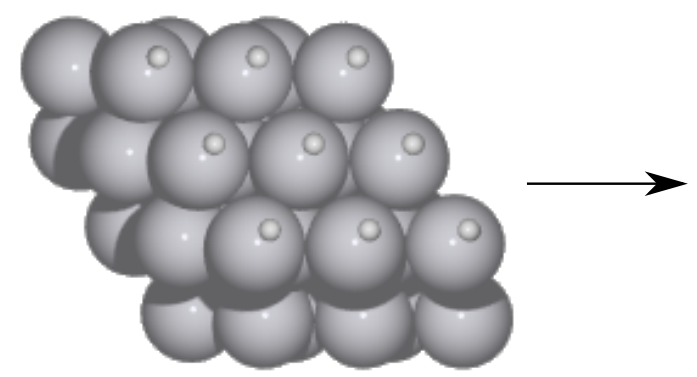

Pt(111)

$1 \mathrm{ML} \mathrm{H*}$ all atop

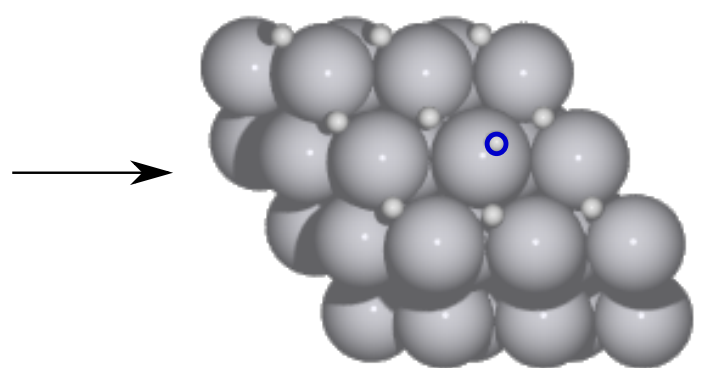

10th $\mathrm{H}^{*}$ is atop $\mathrm{H}^{*}$

$\mathrm{E}_{\mathrm{H}^{*}}=0.34 \mathrm{eV}$

$\mathrm{G}_{\mathrm{H}^{*}}=0.48 \mathrm{eV}$

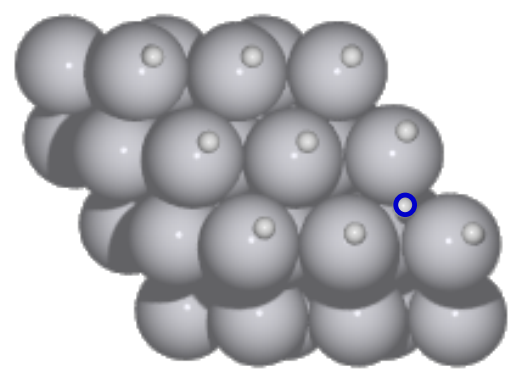

10th $\mathrm{H}^{*}$ is hollow $\mathrm{H}^{*}$

$\mathrm{E}_{\mathrm{H}^{*}}=0.23 \mathrm{eV}$

$\mathrm{G}_{\mathrm{H}^{*}}=0.37 \mathrm{eV}$

Figure S12: Energetic differences between placing the 10th hydrogen on a fully hollowcovered Pt(111) surface compared with a fully atop-covered $\mathrm{Pt}(111)$ surface. There is roughly $0.1 \mathrm{eV}$ difference between placing the 10th $\mathrm{H}^{*}$ in whichever configuration; therefore, we expect trends shown in Figure 1 to hold. 


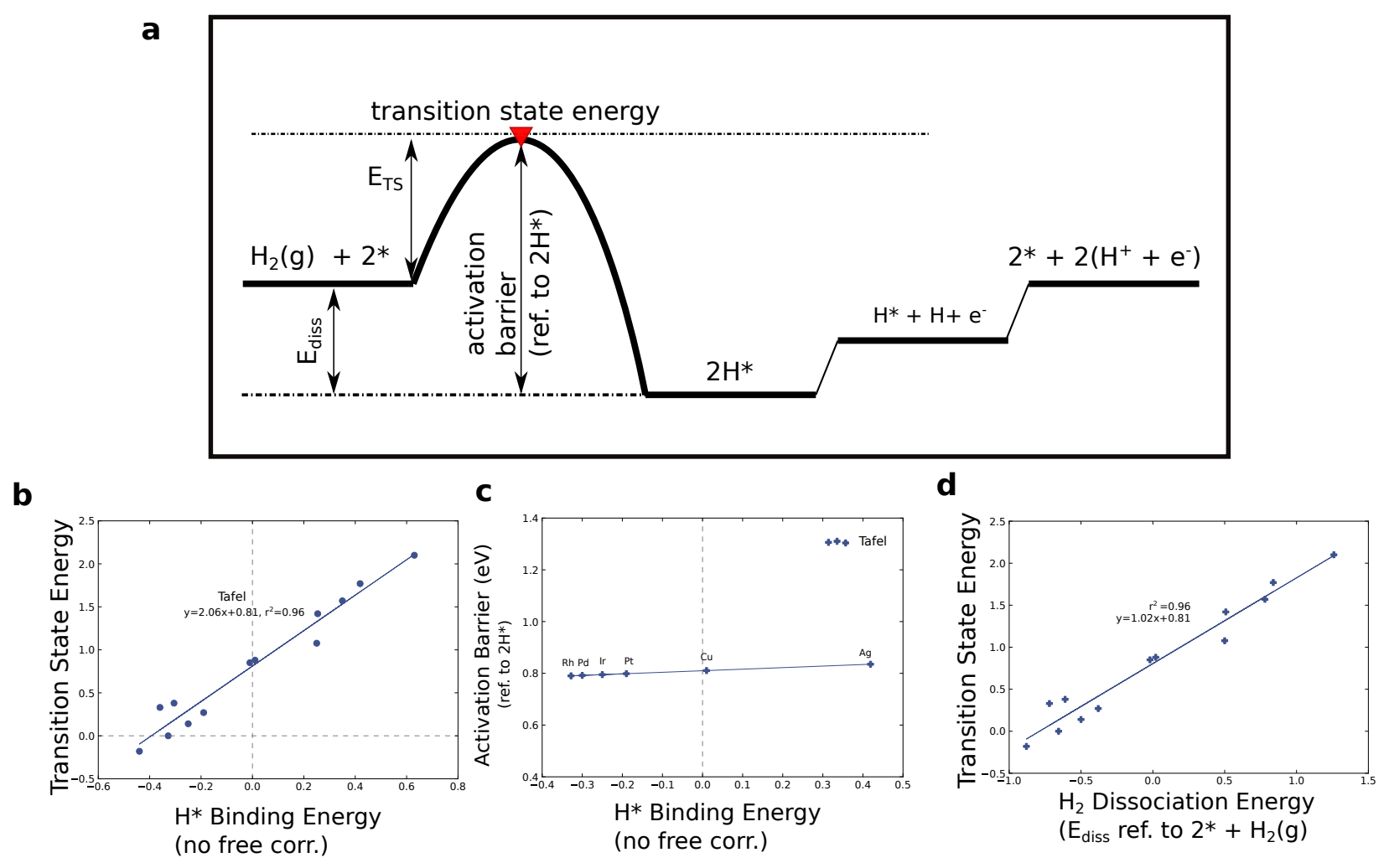

Figure S13: (a) Potential energy diagram notating the transition state energy and barrier term used in this study in relation to the Tafel-Volmer mechanism (note the Volmer barriers are omitted for simplicity). (b) Unscaled Tafel transition state energy vs. $1 \mathrm{H}^{*}$ adsorption energy (same as Figure 2(b) in main text), scaling slope consistent with Tsai et al. ${ }^{4}$ (c) Scaled Tafel barrier vs. $1 H^{*}$ adsorption energy (same as Figure 2(c) in main text) (d) Unscaled Tafel transition state energy vs. $\mathrm{H}_{2}$ dissociation energy (or $2 \mathrm{H}^{*}$ energy), scaling slope consistent with Wang et $\mathrm{al}^{5}$. Unscaled Tafel transition state energies are located in Table S1 and S2 in the SI. 


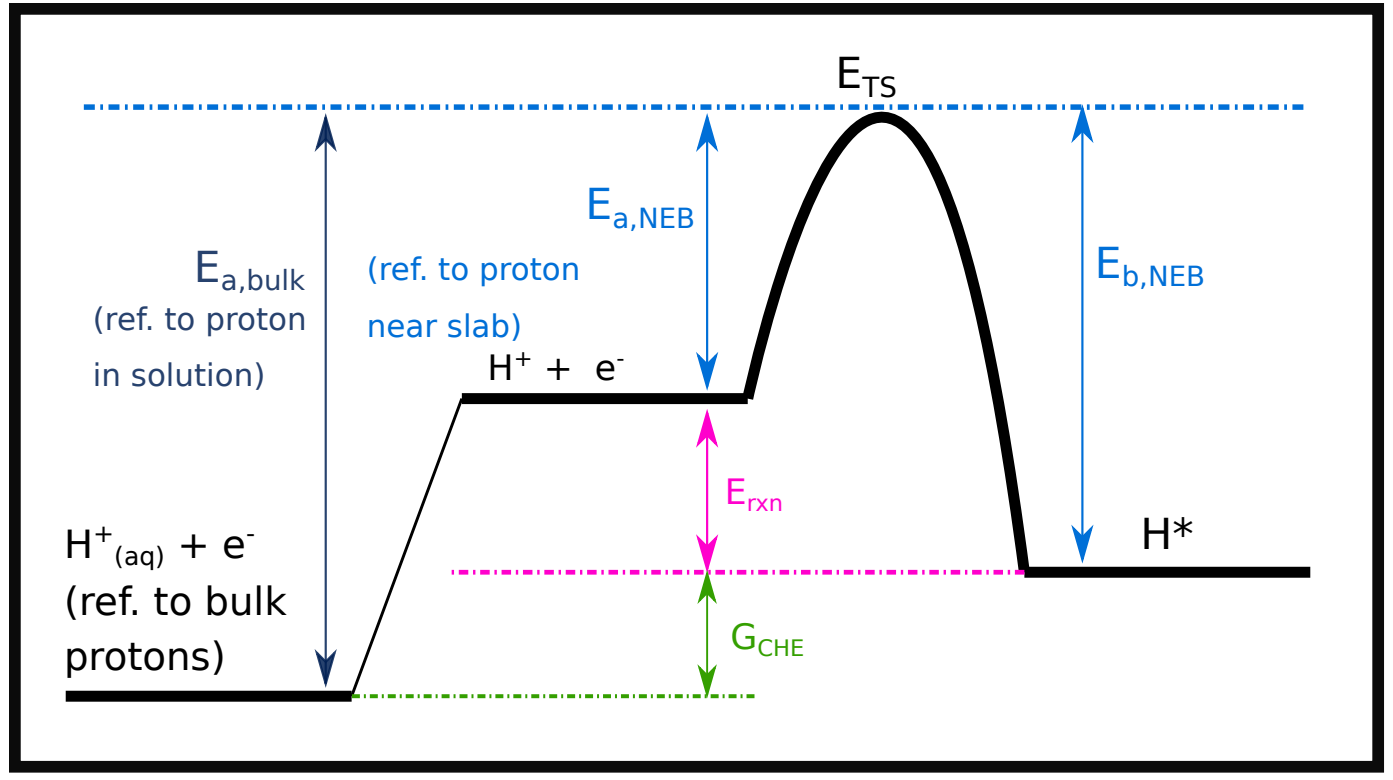

Figure S14: Diagram showing how protons near the surface may not be energetically similar to protons in bulk solution ${ }^{1}$. In this study, we re-reference our forward barriers such that the protons are referenced to bulk solution. This is done by referencing the transition state to the final state, and then referencing the final state to the CHE model.

\section{Computational Hydrogen Electrode}

The computational hydrogen electrode was used to determine the reaction energies as a function of potential. At $\mathrm{U}=0 \mathrm{~V}$ vs. RHE, protons and electrons are at equilibrium with $\mathrm{H}_{2}$ at $101325 \mathrm{~Pa}, 298 \mathrm{~K}$, and all $\mathrm{pH}$ values $\left(\mathrm{H}^{+}+\mathrm{e}^{-} /\right.$leftrightarrow $\left.\frac{1}{2} \mathrm{H}_{2}\right)$. Given applied potential $\mathrm{U}$ :

$$
\mu\left(H^{+}\right)+\mu\left(e^{-}\right)=\frac{1}{2} \mu\left(H_{2}\right)-e U
$$

Excess hydrogens added to the water layer give rise to spontaneous charging of the interface, with electron transfer from hydrogen atoms to the slab. All systems were electroneutral and no compensating homogeneous background charge was applied.

\section{Free energy corrections}

For gaseous species, the electronic energies are corrected using standard ideal-gas methods. The chemical potential is given by:

$$
\mu=E_{\text {elec }}+Z P E+\int C_{p} d T-T * S
$$


where $E_{\text {elec }}$ is the calculated electronic energy, ZPE the zero-point energy, $\int C_{p} d T$ the heat free energy contribution, and $-T S$ the entropic contribution. T is assumed at 298.15 $\mathrm{K}$. We applied in this work the same free energy corrections for gaseous species as in Ref. ${ }^{6}$. In the kinetic model, the $\mathrm{CO}$ pressure was assumed to be $1 \mathrm{mbar}$, based on the estimated partial pressure of $\mathrm{CO}$ given its Faradaic efficiency under $\mathrm{CO}_{2}$ reduction conditions ${ }^{7}$. The free energy of liquid water was determined using the ideal gas approximation at its vapor pressure at room temperature, $3534 \mathrm{~Pa}$. For solvated protons, adsorbed intermediates, and transition states, the harmonic approximation was applied to determine the free energy corrections to the electronic energies.

\section{$5 \quad$ Scaling relations}

The adsorption and transition state energies of reaction intermediates on surfaces often scale with the adsorption energies of a small number of adsorbates (typically one or two), due to trends in the underlying surface electronic structure ${ }^{8}$. In this work, the adsorption energies and transition state energies on (111) surfaces scale linearly with the adsorption energies of $\mathrm{H}^{*}$ on (111) surfaces according to the following equation:

$$
E_{a d s / T S}=\gamma \Delta E_{H *}+b
$$

where the parameters $\gamma$ and $b$ are fitted for each intermediate as a function of the adsorption energies of $\mathrm{H}^{*}$ with all energies being relative to $\mathrm{CO}, \mathrm{H}_{2}$ and $\mathrm{H}_{2} \mathrm{O}$ in the gas phase. The scaling relations considered in this study are as follows:

Volmer (universal): $1.04 \Delta E_{H *}+0.66$ Heyrovsky (universal): $0.87 \Delta E_{H *}+0.49$ Tafel (top-hollow): $2.06 \Delta E_{H *}+0.81$

\section{$6 \quad$ Kinetics}

We took a mean-field approach to microkinetic modelling, where the net rate of an elementary reaction $m \mathrm{~A} \leftrightarrow n \mathrm{~B}$ was given by

$$
r=k_{+} \theta_{A}^{m}-k_{-} \theta_{B}^{n}
$$

where $\theta_{A / B}$ represents the surface coverage of adsorbates $\mathrm{A}$ and $\mathrm{B} . k_{+/-}$represents the rate constants of the forward and backward reaction respectively ${ }^{8}$. The rate constants were calculated through the equation $k=A e^{\frac{-G_{a}}{k^{T}}}$, where $A$ is the reaction prefactor, $G_{a}$ represents the activation barrier, $k_{B}$ is the Boltzmann constant and $T$ the reaction temperature. Site coverages were modeled using the pseudo-steady state approximation (i.e. the rate of change of all surface intermediate is 0$)^{8}$. These assumption were implemented in the CatMAP software package ${ }^{9}$, and used to solve the microkinetic model. 


\section{Adsorbate-Adsorbate Interactions}

Lateral adsorbate-adsorbate interactions were modeled using a first-order expansion in the coverage for the differential adsorption energy:

$$
E_{i}\left(\theta_{i}\right)=E_{i}^{0}+\sum_{j} f \epsilon_{i, j} \theta_{j}
$$

where $E_{i}\left(\theta_{i}\right)$ is the differential adsorption energy of species $i$ given a vector of coverages

$\theta_{i}$. $\quad E_{i}^{0}$ is the differential adsorption energy of species $i$ in the low-coverage limit, $\epsilon_{i, j}$ is a matrix of interaction parameters for the interaction between species $i$ and $j, f$ corresponds to a piecewise linear function for the energy as a function of coverage. The $\mathrm{H}^{*}$ coverage is excluded when calculating $f$ to account for $\mathrm{H}^{*}$ being much smaller than $\mathrm{CO}$ and therefore has little effect on determining the strength of the interactions. Further information on the interaction model is provided in the former work ${ }^{10}$. The adsorbate cross-interaction parameters were determined using DFT calculations of the adsorption energies of intermediates at high coverages on $\mathrm{Pt}(111)$, and were listed below. Convergence of the kinetic model was achieved by first converging the solution with no interactions and incrementally increasing the interaction strength to the fitted value.

- $\epsilon_{C O *, C O *}=2.467$

- $\epsilon_{C O *, H *}=\epsilon_{O H *, H *} 0.73$

- $\epsilon_{C O *, H-H *}=\epsilon_{O H * H-H *}=1.156$

- $\epsilon_{C O *, H-\text { ele* }}=\epsilon_{O H *, H-\text { ele* }}=0.79$

- $\epsilon_{C O *, H 2-\text { ele* }}=\epsilon_{O H *, H 2-\text { ele* }}=0.509$

- $\epsilon_{O H *, O H *}=1.033$

All unlisted $\epsilon_{C O *, H *}$ are assumed to be zero.

\section{Microkinetic reaction steps}

As we are primarily interested in investigating HER in acidic conditions, in this simple model we neglected all the $\mathrm{CO}$ reduction steps, as the selectivity towards $\mathrm{CO}$ reduction in acidic conditions is extremely low. All the elementary steps are described as follows:

- $\mathrm{H}^{+}+\mathrm{e}^{-}+* \leftrightarrow \mathrm{H}^{*}$

- $\mathrm{H}^{+}+\mathrm{e}^{-}+\mathrm{H}^{*} \leftrightarrow \mathrm{H}_{2}(\mathrm{~g})+*$

- $\mathrm{H}^{*}+\mathrm{H}^{*} \leftrightarrow \mathrm{H}_{2}(\mathrm{~g})+2^{*}$

- $\mathrm{OH}^{*}+\mathrm{H}^{+}+\mathrm{e}^{-} \leftrightarrow \mathrm{H}_{2} \mathrm{O}(\mathrm{g})+*$

- $\mathrm{CO}(\mathrm{g})+{ }^{*} \leftrightarrow \mathrm{CO}^{*}$

where ${ }^{*}$ represents a surface site. All the steps had prefactors of $10^{13}$ based on harmonic transition state theory. 


\section{Transfer Coefficient}

According to our simulations (Supplementary Figure S2), the amount of charge transferred in Volmer and Heyrovsky reaction on various metal surfaces ranges from $0.5-0.7$ and therefore there is $\sim 0.2$ uncertainty on the transfer coefficient, $\beta$. This uncertainly primarily arises from the way the transition states are found through the nudge elastic band calculation in conjunction with Bader charge partitioning? ; it was found that transition states closer to the atop site on fcc(111) surfaces generally sway closer to 0.7 charge transferred, whereas transition states closer to the bridge of hollow site sway closer to the 0.5 charge transferred. The uncertainty in $\beta$ values only matters if the Volmer or Heyrovsky transitions differ in their preferred site trajectories; we find that both steps favor atop to bridge-like sites, thus minimizing their effective uncertainty. Supplemental Figure S8 indicate that the change in $\beta$ will slightly affect the optimal HER peak, where the optimal peak shifts $\sim 0.04$ eV every $-0.1 \mathrm{~V}$ applied. However, to maintain consistency, we build our microkinetic models with a beta coefficient of 0.5 for both Volmer and Heyrovsky step.

\section{References}

[1] Chen, L. D.; Bajdich, M.; Martirez, J. M. P.; Krauter, C. M.; Gauthier, J. A.; Carter, E. A.; Luntz, A. C.; Chan, K.; Nørskov, J. K. Understanding the apparent fractional charge of protons in the aqueous electrochemical double layer. Nature Communications 2018, 9, 3202, Number: 1 Publisher: Nature Publishing Group.

[2] Skúlason, E.; Tripkovic, V.; Björketun, M. E.; Gudmundsdóttir, S.; Karlberg, G.; Rossmeisl, J.; Bligaard, T.; Jónsson, H.; Nørskov, J. K. Modeling the Electrochemical Hydrogen Oxidation and Evolution Reactions on the Basis of Density Functional Theory Calculations. J. Phys. Chem. C 2010, 114, 18182-18197.

[3] Van den Bossche, M.; Skúlason, E.; Rose-Petruck, C.; Jónsson, H. Assessment of Constant-Potential Implicit Solvation Calculations of Electrochemical Energy Barriers for H2 Evolution on Pt. J. Phys. Chem. C 2019, 123, 4116-4124, Publisher: American Chemical Society.

[4] Tsai, C. et al. Direct Water Decomposition on Transition Metal Surfaces: Structural Dependence and Catalytic Screening. Catal Lett 2016, 146, 718-724.

[5] Wang, S. et al. Universal transition state scaling relations for (de)hydrogenation over transition metals. Phys. Chem. Chem. Phys. 2011, 13, 20760-20765, Publisher: The Royal Society of Chemistry. 
[6] Liu, X.; Xiao, J.; Peng, H.; Hong, X.; Chan, K.; Nørskov, J. K. Understanding trends in electrochemical carbon dioxide reduction rates. Nature Communications 2017, 8, 15438 .

[7] Peterson, A. A.; Abild-Pedersen, F.; Studt, F.; Rossmeisl, J.; Nørskov, J. K. How copper catalyzes the electroreduction of carbon dioxide into hydrocarbon fuels. Energy Environ. Sci. 2010, 3, 1311-1315.

[8] Nørskov, J. K.; Studt, F.; Abild-Pedersen, F.; Bligaard, T. Fundamental Concepts in Heterogeneous Catalysis; John Wiley \& Sons, 2014.

[9] Medford, A. J.; Shi, C.; Hoffmann, M. J.; Lausche, A. C.; Fitzgibbon, S. R.; Bligaard, T.; Nørskov, J. K. CatMAP: A Software Package for Descriptor-Based Microkinetic Mapping of Catalytic Trends. Catal Lett 2015, 145, 794-807.

[10] Shi, C.; Hansen, H. A.; Lausche, A. C.; Nørskov, J. K. Trends in electrochemical CO2 reduction activity for open and close-packed metal surfaces. Phys. Chem. Chem. Phys. 2014, 16, 4720-4727. 